\title{
Tumor carcinoide testicular asociado a teratoma: A propósito de un caso
}

\author{
Martínez Ballesteros C*, Del Portillo Sánchez L*, Sánchez Yuste R**, Sola Galarza I*, \\ Martínez Salamanca JI*, Carballido Rodríguez J*.
}

*Servicio de Urología H. U. Puerta de Hierro, Madrid. **Servicio de Anatomía Patológica. Hospital Universitario Puerta de Hierro. Madrid.

Actas Urol Esp. 2008:32(4):458-460

\begin{abstract}
RESUMEN
TUMOR CARCINOIDE TESTICULAR ASOCIADO A TERATOMA: A PROPÓSITO DE UN CASO

Se presenta un caso de tumor carcinoide de origen testicular asociado a teratoma maduro en un varón de 31 años de edad. La localización gonadal primaria de este tumor es poco usual y más aún, asociado a teratoma. El diagnóstico y tratamiento precoces condicionan el pronóstico de los sujetos afectados por este tipo de neoplasia ya que, el único tratamiento potencialmente curativo es la cirugía. El seguimiento debe prolongarse durante años, debido a la posibilidad de desarrollar metástasis de modo tardío.

Palabras clave: Tumor carcinoide testicular. Teratoma testicular.
\end{abstract}

\section{ABSTRACT \\ TESTICULAR CARCINOID TUMOR ASSOCIATED WITH TERATOMA: WITH REGARD TO A CASE}

We report a case of a carcinoid tumor originated in testicle associated with mature teratoma in a 31 years old male. Primary gonadal location of this tumor is unusual, moreover when associated with teratoma. Early diagnosis and treatment determine the prognostic of the patients affected of this neoplasm since the only curative potential treatment is surgery. Follow up must be extent for years due to the possibility of late relapse.

Keywords: Testicular carcinoid tumor. Testicular teratoma.

$\mathrm{E}$ hallazgo de un tumor carcinoide (TC) de localización primaria testicular es una rara entidad clínica. Entre las referencias bibliográficas se encuentran menos de un centenar de casos comunicados. La mayor parte de las ocasiones en que se encuentra un TC de localización testicular corresponde a una afectación metastática de este tumor, cuyo origen se sitúa a nivel pulmonar o gastrointestinal. La localización genitourinaria primaria de este proceso es muy poco frecuente y, concretamente, a nivel testicular. La localización primaria testicular representa un $0,2 \%$ del total de neoplasias originadas en el testículo ${ }^{1}$. Cuando el TC se origina en el testículo, suele hacerlo de forma pura, siendo aún más infrecuente el hallazgo de un teratoma asociado al TC. Hasta la fecha apenas una quincena casos de TC asociado a teratoma han sido publicados.

\section{CASO CLÍNICO}

Presentamos el caso de un varón de 31 años que consulta por la aparición de una tumoración indolora, en hemiescroto derecho, de tres semanas de evolución.

- Exploración física: se palpa un nódulo de aproximadamente $1,5 \mathrm{~cm}$ de diámetro que produce irregularidad en la albugínea y de consistencia pétrea.

- Ecografía escrotal: se describe una formación sólida, lobulada, de $12 \times 8 \mathrm{~mm}$, localizada superficialmente en el polo superior del testículo derecho, con un área hipoecogénica y algunas microcalcificaciones aisladas.

- Análisis bioquímico: parámetros bioquímicos de función renal y hepática, así como marcadores tumorales habituales para las neoplasias germinales (Alfa-Fetoproteína, Beta-HCG y LDH) dentro de los límites considerados normales para el laboratorio de referencia. 
Ante los hallazgos descritos y bajo anestesia general, se lleva a cabo una orquiectomía radical por vía inguinal con colocación de prótesis testicular de silicona (Mentor Silicone Elastomen Medium ${ }^{\circledR}$ ).

La descripción macroscópica de la pieza muestra una lesión en polo superior de testículo derecho, bien delimitada de $1.2 \mathrm{~cm}$ de diámetro que muestra áreas quísticas y sólidas amarillentas que contactan con la albuginea. Microscópicamente, se observan elementos maduros de tejido tiroideo, tejido adiposo, epitelio glandular y tejido cartilaginoso como componentes del teratoma (Figs. 1 y 2). El tumor carcinoide mide $1,1 \times 0,8 \mathrm{~cm}$, es de tipo acinar (Fig. 3) y no infiltra la albugínea, la rete testis ni se aprecia invasión vascular. La determinación mediante técnicas inmunohistoquímicas en el área de tumor carcinoide de

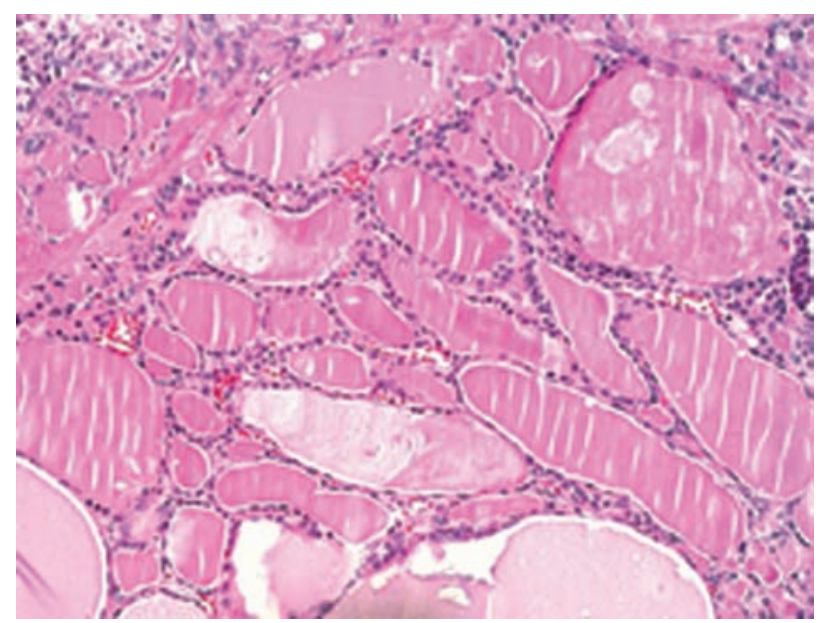

FIGURA 1. Imagen que muestra abundante parénquima tiroideo en forma de foliculos. Nótese que en el margen superiorizquierdo se aprecia una sección de túbulo seminifero.

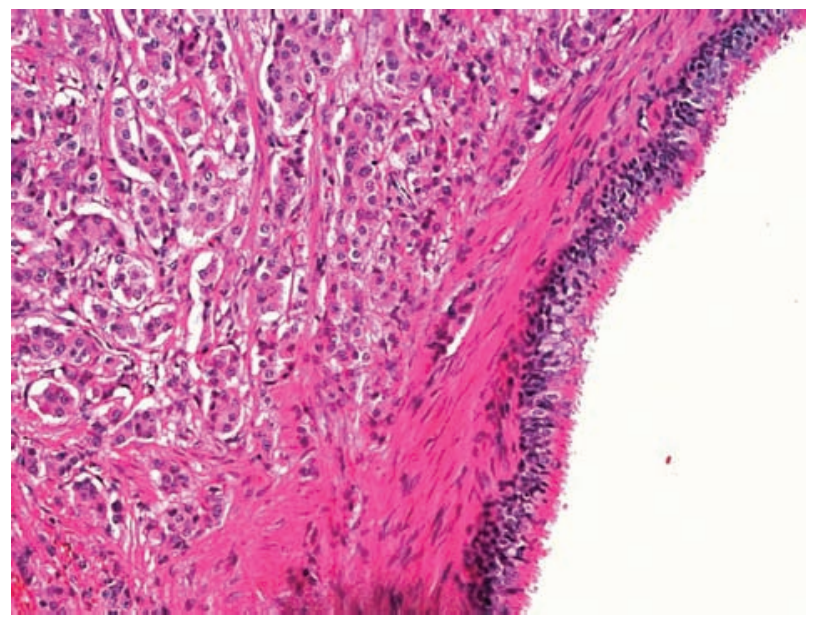

FIGURA 2. Coexistencia de tumor carcinoide (izquierda) y revestimiento epitelial respiratorio del teratoma.

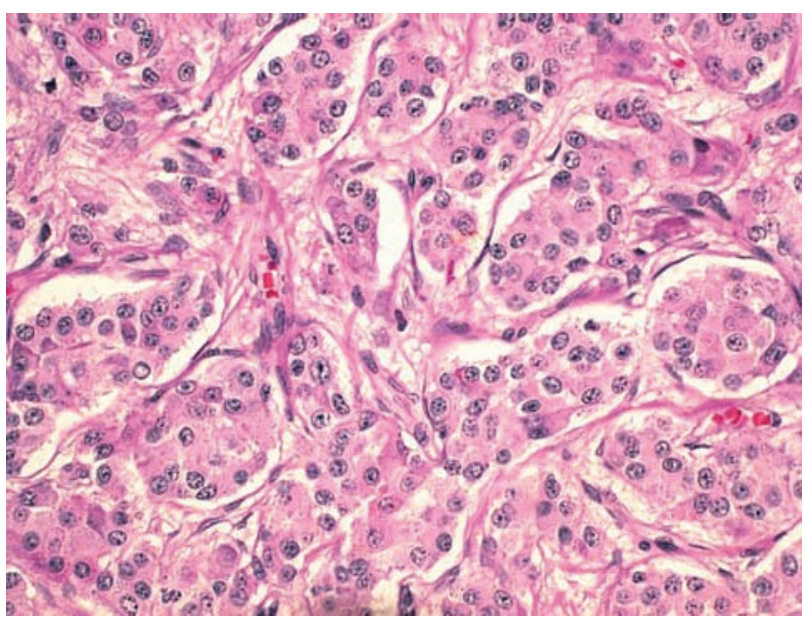

FIGURA 3. Microfotografia del área de carcinoide que muestra un patrón organoide y escasa atipia celular.

citoqueratinas, cromogranina y sinaptofisina resultan positivas, siendo negativas para inhibina, PLAP, c-kit y alfafetoproteína.

El estudio postoperatorio incluye la determinación plasmática de marcadores tumorales germinales (Alfa-Fetoproteína, Beta-HCG y LDH), perfil hormonal tiroideo, cortisol libre urinario, ácido 5-hidroxiindolacético (5-HIIA) plasmático y urinario, cromogranina A y serotonina séricas, resultando todos los parámetros dentro de los niveles considerados normales para el laboratorio de referencia. El estudio de extensión se completa con la realización de una TAC toracoabdominal y un Octeoscan con In 111 , que no revelan indicios de enfermedad metastática ni acúmulos considerados patológicos del radiotrazador. Actualmente, el paciente se encuentra libre de enfermedad tras 4 años de seguimiento.

\section{DISCUSIÓN}

El primer caso de TC testicular es publicado por Cope en 1930, tratándose de una forma metastática, mientras que el primer caso de origen testicular primario data de 1954 a cargo de Simonds et $\mathrm{al}^{5}$. Entre las referencias bibliográficas consultadas se encuentran 14 casos en los que al TC se asocia un teratoma maduro, como es el caso presentado ${ }^{1}$.

Recientemente se ha postulado que el origen del TC testicular primario puede situarse en la misma célula progenitora de la que derivan las células de Leydig, aportando este hallazgo algo de luz al poco conocido origen este tipo de tumores ${ }^{2}$. Merino et al publican el primer caso de carcinoide testicular puro con metástasis ganglionar y síndrome carci- 
noide asociado, hallando en el estudio de la pieza histológica la presencia de neoplasia intratubular de células germinales confirmada por la positividad a OCT4 y PLAP, lo que refuerza la idea del origen primario testicular y no metastático ${ }^{4}$. Estos autores postulan un doble origen del TC: de células argentafines, que no están presentes en el testículo y de células germinales, hipótesis ésta que coincide con la expuesta por Mai et $\mathrm{al}^{2}$. Asímismo, concluyen que la forma pura es más frecuente que la forma asociada a teratoma, suponiéndose al TC testicular como la evolución de un teratoma maduro "quemado" ("burn out") 4 .

El único tratamiento potencialmente curativo es la orquiectomía radical y la exéresis de sus metástasis si es que existieran, si bien, la linfadenectomía retroperitoneal de estadificación no es un procedimiento desarrollado por la mayoría de los autores que han comunicado casos similares al nuestro ${ }^{1,3}$.

Respecto al análisis microscópico, aún no se conocen con exactitud los factores que puedan predecir un comportamiento más agresivo, aunque Fujita et al establecen que el tamaño tumoral superior a $7,3 \mathrm{~cm}$, la escasa diferenciación celular y la presencia de síndrome carcinoide asociado son factores predictores independientes para el desarrollo de metástasis ganglionares ${ }^{1}$. Respecto a los procedimientos necesarios para el estudio de extensión, es preciso realizar una TAC abdominopélvico, estudio radiológico simple de tórax y octeoscan si está disponible, además de monitorizar los niveles plasmáticos de 5-HIIA y serotonina.

Hay que destacar que la característica más reseñable del TC radica en lo ominoso de su pronóstico en caso de presentar enfermedad metastática ya que, hasta la fecha, los distintos regímenes de tratamiento sistémico basado en agentes quimioterápicos (incluyendo platinos y antraciclinas) tan sólo han demostrado lograr respuestas parciales en menos del $10 \%$ de los sujetos tratados ${ }^{1}$. La tendencia a la diseminación es más acusada cuando la localización primaria es gastrointestinal o pulmonar, situándose en torno al $11 \%$ si el origen es testicular $^{5,12}$.

Estos últimos protagonizan el seguimiento frente a cualquier prueba de imagen realizada periódicamente ante su escasa rentabilidad ${ }^{1,8}$. El seguimiento de estos pacientes debe prolongarse ante la capacidad de metastatizar hasta 10 años tras el diagnóstico inicial ${ }^{5,8}$. El caso que se presenta, muestra niveles plasmáticos, tanto de 5-HIIA como de serotonina, en los límites normales tras 48 meses de seguimiento, así como negatividad en las pruebas de imagen realizadas con periodicidad. De esta manera, se presenta un caso de tumor carcinoide de localización testicular primaria con una supervivencia prolongada.

\section{REFERENCIAS}

1. Fujita K, Wada R, Sakurai T, Sashide K, Fujime M. Primary carcinoid of the testis with teratoma metastatic to the para-aortic lymph node. Int J Urol. 2005;12(3):328-331.

2. Mai KT, Park PC, Yazdi HM, Carlier M. Leydig cell origin of testicular carcinoid tumour: immunohistochemical and electron microscopic evidence. Histopathology 2006;49(5):548-549.

3. Blumberg JM, Sedberry S, Kazmi SO. Bilateral asynchronous metastatic carcinoid tumor of the testis. Urology 2005;65(1): 174.

4. Merino J, Zuluaga A, Gutierrez-Tejero F, Del Mar Serrano M, Ciani S, Nogales FF. Pure testicular carcinoid associated with intratubular germ cell neoplasia. J Clin Pathol. 2005;58(12): 1331- 1333 .

5. Hodzic J, Golka K, Schulze H.. Primary testicular carcinoid. Med Sci Monit. 2004 Aug; 10(8):CS46-48.

6. Yamasaki T, Yagihashi Y, Shirahase T, Hashimura T, Watanabe C.. Primary carcinoid tumor arising in a retroperitoneal mature teratoma in an adult. Int J Urol. 2004;11(10):912-915.

7. Kato N, Motoyama T, Kameda N, Hiruta N, Emura I, Hasegawa G, et al T. Primary carinoid tumor of the testis: immunohistochemical, ultraestructural and FISH analysis with review of the literature. Pathol Int. 2003;53(10):680-685.

8. Fucs M, Romero FR, Germanos de Castro M, de Carvalho Fernandes R, Camara-Lopes LH, Cardenuto Perez MD. Testicular metastasis 10 years after resection of appendiceal carcinoid. Urology 2005;65(3):591.

9. Berdjis CC, Mostofi FK.. Carcinoid tumors of the testis. J Urol 1977:118(5):777-782

10. Zavala-Pompa A, Ro JY, el-Naggar A, Ordóñez NG, Amin MB, Pierce PD, Ayala AG. Primary carcinoid tumor of testis. Immunohistochemical, ultraestructural and DNA flow cytometric study of three cases with a review of the literature. Cancer 1993;72(5):1726-1732.

11. Umeda T, Tokuda H, Hara T, Kishi H, Niijima T. Primary testicular carcinoid tumor in a 19-year-old boy. Eur Urol. 1987; 13(3):215-216.

12. Reyes A, Moran CA, Suster S, Michal M, Dominguez H. Neuroendocrine carcinomas (carcinoid tumor) of the testis. A clinicopathologic and immunohistochemical study of ten cases. Am J Clin Pathol. 2003;120(2):182-187.

Correspondencia autor: Dr. C. Martínez Ballesteros

Servicio de Urología. Hospital Puerta de Hierro. Madrid.

San Martín de Porres, 4 - 28035 Madrid. Tel: 913445000

E-mail autor: rmedioba@yahoo.es

Información artículo: Nota clínica

Trabajo recibido: febrero 2008

Trabajo aceptado: marzo 2008 